\title{
Some fixed point theorems for contractive multi- valued mappings induced by generalized distance in metric spaces
}

Soawapak Hirunworakit ${ }^{1}$ and Narin Petrot ${ }^{1,2^{*}}$

\author{
* Correspondence: narinp@nu.ac.th \\ ${ }^{1}$ Department of Mathematics, \\ Faculty of Science, Naresuan \\ University, Phitsanulok 65000, \\ Thailand \\ Full list of author information is \\ available at the end of the article
}

\begin{abstract}
The purpose of this paper is to prove some existence theorems for fixed point problem by using a generalization of metric distance, namely u-distance. Consequently, some special cases are discussed and an interesting example is also provided. Presented results are generalizations of the important results due to Ume (Fixed Point Theory Appl 2010(397150), 21 pp, 2010) and Suzuki and Takahashi (Topol Methods Nonlinear Anal 8, 371-382, 1996).

2010 Mathematics Subject Classification: 47H09, 47H10.
\end{abstract}

Keywords: complete metric space, generalized multi-valued contractive, u-distance, fixed point.

\section{Introduction and preliminaries}

Let $(X, d)$ be a metric space. A mapping $T: X \rightarrow X$ is said to be contraction if there exists $r \in[0,1)$ such that

$$
d(T(x), T(y)) \leq r d(x, y), \quad \forall x, y \in X .
$$

In 1922, Banach [1] proved that if $(X, d)$ is a complete metric space and the mapping $T$ satisfies (1.1), then $T$ has a unique fixed point, that is $T(u)=u$ for some $u \in X$. Such a result is well known and called the Banach contraction mapping principle. Following the Banach contraction principle, Nadler Jr. [2] established the fixed point result for multi-valued contraction maps, which in turn is a generalization of the Banach contraction principle. Since then, there are several extensions and generalizations of these two important principles, see [3,4] and [5-11] for examples.

In 1996, Kada et al. [4] introduced the concept of $w$-distance on a metric space ( $X$, d). By using such a $w$-distance concept, they improved some important theorems such as Caristi's fixed point theorem, Ekeland's variational principle and the nonconvex minimization theorem. Recently, Suzuki [7] introduced the concept of generalization metric distance, which is called $\tau$-distance. By using concepts of $\tau$-distance, he proved some results on fixed point problems and also showed that the class of $w$-distance is properly contained in the class of $\tau$-distance. Most recently, Ume [11] introduced another concept of distance as the following.

(c) 2011 Hirunworakit and Petrot; licensee Springer. This is an Open Access article distributed under the terms of the Creative Commons Attribution License (http://creativecommons.org/licenses/by/2.0), which permits unrestricted use, distribution, and reproduction in any medium, provided the original work is properly cited. 
Definition 1.1. [11]. Let $(X, d)$ be a metric space. Then, a function $p: X \times X \rightarrow[0$, $\infty)$ is called $u$-distance on $X$ if there exists a function $\theta: X \times X \times[0, \infty) \times[0, \infty) \rightarrow[0$, $\infty)$ such that

(u1) $p(x, z) \leq p(x, y)+p(y, z)$ for all $x, y, z \in X$;

(u2) $\theta(x, y, 0,0)=0$ and $\theta(x, y, s, t) \geq \min \{s, t\}$ for all $x, y \in X$ and $s, t \in[0, \infty)$, and for any $x \in X$ and for every $\varepsilon>0$, there exists $\delta>0$ such that $\left|s-s_{0}\right|<\delta$, $\mid t$ $t_{0} \mid<\delta, s, s_{0}, t, t_{0} \in[0, \infty)$ and $y \in X$ imply

$\left|\theta(x, y, s, t)-\theta\left(x, y, s_{0}, t_{0}\right)\right|<\varepsilon ;$

(u3)

$$
\begin{gathered}
\lim _{n \rightarrow \infty} x_{n}=x \\
\lim _{n \rightarrow \infty} \sup \left\{\theta\left(w_{n}, z_{n}, p\left(w_{n}, x_{m}\right), p\left(z_{n}, x_{m}\right)\right): m \geq n\right\}=0
\end{gathered}
$$

imply

$$
p(y, x) \leq \liminf _{n \rightarrow \infty} p\left(y, x_{n}\right) \text { for all } y \in X
$$

(u4)

$$
\begin{gathered}
\lim _{n \rightarrow \infty} \sup \left\{p\left(x_{n}, w_{m}\right): m \geq n\right\}=0, \\
\lim _{n \rightarrow \infty} \sup \left\{p\left(y_{n}, z_{m}\right): m \geq n\right\}=0, \\
\lim _{n \rightarrow \infty} \theta\left(x_{n}, w_{n}, s_{n}, t_{n}\right)=0, \\
\lim _{n \rightarrow \infty} \theta\left(y_{n}, z_{n}, s_{n}, t_{n}\right)=0
\end{gathered}
$$

imply

$$
\lim _{n \rightarrow \infty} \theta\left(w_{n}, z_{n}, s_{n}, t_{n}\right)=0
$$

or

$$
\begin{gathered}
\lim _{n \rightarrow \infty} \sup \left\{p\left(w_{m}, x_{n}\right): m \geq n\right\}=0, \\
\lim _{n \rightarrow \infty} \sup \left\{p\left(z_{m}, y_{n}\right): m \geq n\right\}=0, \\
\lim _{n \rightarrow \infty} \theta\left(x_{n}, w_{n}, s_{n}, t_{n}\right)=0, \\
\lim _{n \rightarrow \infty} \theta\left(y_{n}, z_{n}, s_{n}, t_{n}\right)=0
\end{gathered}
$$


imply

$$
\lim _{n \rightarrow \infty} \theta\left(w_{n}, z_{n}, s_{n}, t_{n}\right)=0
$$

(u5)

$$
\begin{aligned}
& \lim _{n \rightarrow \infty} \theta\left(w_{n}, z_{n}, p\left(w_{n}, x_{n}\right), p\left(z_{n}, x_{n}\right)\right)=0, \\
& \lim _{n \rightarrow \infty} \theta\left(w_{n}, z_{n}, p\left(w_{n}, y_{n}\right), p\left(z_{n}, y_{n}\right)\right)=0
\end{aligned}
$$

imply

$$
\lim _{n \rightarrow \infty} d\left(x_{n}, y_{n}\right)=0
$$

or

$$
\begin{aligned}
& \lim _{n \rightarrow \infty} \theta\left(a_{n}, b_{n}, p\left(x_{n}, a_{n}\right), p\left(x_{n}, b_{n}\right)\right)=0, \\
& \lim _{n \rightarrow \infty} \theta\left(a_{n}, b_{n}, p\left(y_{n}, a_{n}\right), p\left(y_{n}, b_{n}\right)\right)=0
\end{aligned}
$$

imply

$$
\lim _{n \rightarrow \infty} d\left(x_{n}, y_{n}\right)=0 .
$$

We give the following remark and example, which can be found in [11].

Remark 1.2. Suppose that $\theta: X \times X \times[0, \infty) \times[0, \infty) \rightarrow[0, \infty)$ is a mapping satisfying $(u 2) \sim(u 5)$. Then, there exists a mapping $\eta: X \times X \times[0, \infty) \times[0, \infty) \rightarrow[0, \infty)$ such that $\eta$ is nondecreasing in its third and fourth variable, respectively, satisfying $(u 2) \eta \sim$ $(u 5) \eta$, where $(u 2) \eta \sim(u 5) \eta$ stand for substituting $\eta$ for $\theta$ in $(u 2) \sim(u 5)$, respectively.

Example 1.3. Let $p$ be a $\tau$-distance on metric space $(X, d)$, then $p$ is also a $u$-distance on $X$. On the other hand, let $(X,\|\cdot\|)$ be a normed space then a function $p: X \times X \rightarrow$ $[0, \infty)$ defined by $p(x, y)=\|x\|$ for every $x, y \in X$ is a $u$-distance on $X$ but not a $\tau$-distance. These imply that the class of $\tau$-distance is properly contained in the class of $u$ distance.

In this paper, we will prove some fixed point theorems in metric spaces by using such a $u$-distance concept. Consequently, as shown by Example 1.3, our results generalize many of the existing results presented in metric spaces. Indeed, it provides more choices of tool implements to check whether a fixed point of considered mapping exists.

Our main results are concerned with the following class of mappings.

Definition 1.4. Let $(X, d)$ be a metric space and $2^{X}$ be a set of all nonempty subset of $X$. A multi-valued mapping $T: X \rightarrow 2^{X}$ is called $p$-contractive if there exist a $u$ - 
distance $p$ on $X$ and $r \in[0,1)$ such that for any $x_{1}, x_{2} \in X$ and $y_{1} \in T\left(x_{1}\right)$ there is $y_{2} \in$ $T\left(x_{2}\right)$ such that

$$
p\left(y_{1}, y_{2}\right) \leq r p\left(x_{1}, x_{2}\right)
$$

Remark 1.5. Definition 1.4 was introduced and its fixed point theorems were proved in [9], but by using the concept of $w$-distance. Note that in the case $p=d$, the mapping $T$ is called a contraction.

We now recall some basic concepts and well-known results.

Definition 1.6. [11]. Let $(X, d)$ be a metric space and $p$ be a $u$-distance on $X$. Then, a sequence $\left\{x_{n}\right\}$ of $X$ is called $p$-Cauchy sequence if there exists a sequence $\left\{z_{n}\right\}$ of $X$ such that

$$
\lim _{n \rightarrow \infty} \sup \left\{\theta\left(z_{n}, z_{n}, p\left(z_{n}, x_{m}\right), p\left(z_{n}, x_{m}\right)\right): m \geq n\right\}=0,
$$

or

$$
\lim _{n \rightarrow \infty} \sup \left\{\theta\left(z_{n}, z_{n}, p\left(x_{m}, z_{n}\right), p\left(x_{m}, z_{n}\right)\right): m \geq n\right\}=0 .
$$

where $\theta: X \times X \times[0, \infty) \times[0, \infty) \rightarrow[0, \infty)$ is a function satisfying $(u 2) \sim(u 5)$ for a $u$ distance $p$.

Lemma 1.7. [11]. Let $(X, d)$ be a metric space and let $p$ be a $u$-distance on $X$. Suppose that a sequence $\left\{x_{n}\right\}$ of $X$ satisfies

$$
\lim _{n \rightarrow \infty} \sup \left\{p\left(x_{n}, x_{m}\right): m \geq n\right\}=0 \text {. }
$$

or

$$
\lim _{n \rightarrow \infty} \sup \left\{p\left(x_{m}, x_{n}\right): m \geq n\right\}=0 .
$$

Then, $\left\{x_{n}\right\}$ is a $p$-Cauchy sequence.

Lemma 1.8. [11]. Let $(X, d)$ be a metric space and let $p$ be a $u$-distance on $X$. If $\left\{x_{n}\right\}$ is a $p$-Cauchy sequence, then $\left\{x_{n}\right\}$ is a Cauchy sequence.

Lemma 1.9. [11]. Let $(X, d)$ be a metric space and let $p$ be a $u$-distance on $X$. Let $x$, $y \in X$. If there exists $z \in X$ such that $p(z, x)=0$ and $p(z, y)=0$, then $x=y$.

Definition 1.10. Let $(X, d)$ be a metric space and $T: X \rightarrow 2^{X}$ be a mapping. For any fixed $x_{0} \in X$, a sequence $\left\{x_{n}\right\}=\left\{x_{0}, x_{1}, x_{2}, \ldots\right\} \subset X$ such that $x_{n+1} \in T\left(x_{n}\right)$ is called an orbit of $x_{0}$ with respect to mapping $T$. We will denote by $\mathcal{O}\left(T, x_{0}\right)$ the set of all orbital sequences of $x_{0}$ with respect to mapping $T$.

\section{Main results}

From now on, in view of Remark 1.2, if $\theta: X \times X \times[0, \infty) \times[0, \infty) \rightarrow[0, \infty)$ is a mapping satisfying $(u 2) \sim(u 5)$ for the considered $u$-distance, we will always understand that $\theta$ is a nondecreasing function in its third and fourth variables.

Inspired by an idea presented by Suzuki [8], we have an important tool for proving our main result.

Lemma 2.1. Let $(X, d)$ be a metric space and let $p$ be a $u$-distance on $X$. If $\left\{x_{n}\right\}$ is a $p$-Cauchy sequence and $\left\{y_{n}\right\}$ is a sequence satisfying

$$
\lim _{n \rightarrow \infty} \sup \left\{p\left(x_{n}, y_{m}\right): m \geq n\right\}=0,
$$


then $\left\{y_{n}\right\}$ is also a $p$-Cauchy sequence and $\lim _{n \rightarrow \infty} d\left(x_{n}, y_{n}\right)=0$.

Proof. Let $\theta: X \times X \times[0, \infty) \times[0, \infty) \rightarrow[0, \infty)$ satisfying $(u 2) \sim(u 5)$ for a $u$-distance $p$. Since $\left\{x_{n}\right\}$ is a $p$-Cauchy sequence, there exists a sequence $\left\{z_{n}\right\}$ of $X$ such that

$$
\lim _{n \rightarrow \infty} \sup \left\{\theta\left(z_{n}, z_{n}, p\left(z_{n}, x_{m}\right), p\left(z_{n}, x_{m}\right): m \geq n\right\}=0 .\right.
$$

Now, let $\left\{y_{n}\right\}$ be a sequence satisfying $\lim _{n \rightarrow \infty} \sup \left\{p\left(x_{n}, y_{m}\right): m \geq n\right\}=0$. Let us put

$$
\alpha_{n}=\sup \left\{p\left(z_{n}, x_{m}\right): m \geq n\right\},
$$

and

$$
\beta_{n}=\sup \left\{p\left(x_{i}, y_{j}\right): j>i \geq n\right\} .
$$

We note that $\left\{\beta_{n}\right\}$ is a nonincreasing sequence and converge to 0 . Thus, from (u2) we can define a strictly increasing function $f$ from $\mathbb{N}$ into itself such that

$$
\theta\left(z_{n}, z_{n}, \alpha_{n}+\beta_{f(n)}, \alpha_{n}+\beta_{f(n)}\right) \leq \theta\left(z_{n}, z_{n}, \alpha_{n}, \alpha_{n}\right)+\frac{1}{n^{\prime}}
$$

for all $n \in \mathbb{N}$. Using such a function $f$, we now define a function $g: \mathbb{N} \rightarrow \mathbb{N}$ by

$$
g(n)= \begin{cases}1, & \text { if } n<f(1), \\ k, & \text { if } f(k) \leq n<f(k+1) \text { for some } k \in \mathbb{N} .\end{cases}
$$

Then, we can see that

- $g(n) \leq f(g(n)) \leq n$ for all $n \in \mathbb{N}$ with $g(n) \geq 2$.

- $\theta\left(z_{g(n)}, z_{g(n)}, \alpha_{g(n)}+\beta_{n}, \alpha_{g(n)}+\beta_{n}\right) \leq \theta\left(z_{g(n)}, z_{g(n)}, \alpha_{g(n)}, \alpha_{g(n)}\right)+\frac{1}{g(n)}$.

- $\lim _{n \rightarrow \infty} g(n)=\infty$.

Now we consider

$$
\begin{aligned}
& \limsup _{n \rightarrow \infty} \sup \left\{\theta\left(z_{g(n)}, z_{g(n)}, p\left(z_{g(n)}, y_{m}\right), p\left(z_{g(n)}, y_{m}\right)\right): m \geq n\right\} \\
& \leq \limsup _{n \rightarrow \infty} \sup \left\{\theta\left(z_{g(n)}, z_{g(n)}, p\left(z_{g(n)}, x_{n}\right)+p\left(x_{n}, y_{m}\right), p\left(z_{g(n)}, x_{n}\right)+p\left(x_{n}, y_{m}\right)\right): m \geq n\right\} \\
& \leq \limsup _{n \rightarrow \infty} \theta\left(z_{g(n)}, z_{g(n)}, \alpha_{g(n)}+\beta_{n}, \alpha_{g(n)}+\beta_{n}\right) \\
& \leq \lim _{n \rightarrow \infty}\left[\theta\left(z_{g(n)}, z_{g(n)}, \alpha_{g(n)}, \alpha_{g(n)}\right)+\frac{1}{g(n)}\right] \\
& =0 .
\end{aligned}
$$

This means $\left\{y_{n}\right\}$ is a $p$-Cauchy sequence. Furthermore, since

$$
\limsup _{n \rightarrow \infty} \theta\left(z_{g(n)}, z_{g(n)}, p\left(z_{g(n)}, x_{n}\right), p\left(z_{g(n)}, x_{n}\right)\right) \leq \lim _{n \rightarrow \infty} \theta\left(z_{g(n)}, z_{g(n)}, \alpha_{g(n)}, \alpha_{g(n)}\right)=0,
$$

we have $\lim _{n \rightarrow \infty} d\left(x_{n}, y_{n}\right)=0$, by $(u 5)$. This completes the proof.

Now we present our main results, which are related to $p$-contractive mapping.

Lemma 2.2. Let $(X, d)$ be a metric space and let $T: X \rightarrow 2^{X}$ be a p-contractive mapping. Then, for each $u_{0} \in X$, there exists an orbit $\left\{u_{n}\right\} \in \mathcal{O}\left(T, u_{0}\right)$ such that 


$$
\lim _{n \rightarrow \infty} \sup \left\{p\left(u_{n}, u_{m}\right): m \geq n\right\}=0 .
$$

Consequently, $\left\{u_{n}\right\}$ is a p-Cauchy sequence.

Proof. Let $u_{0} \in X$ be arbitrary and $u_{1} \in T\left(u_{0}\right)$ be chosen. Then, by $T$ as a $p$-contractive mapping, there exists $u_{2} \in T\left(u_{1}\right)$ such that

$$
p\left(u_{1}, u_{2}\right) \leq r p\left(u_{0}, u_{1}\right) .
$$

For this $u_{2} \in T\left(u_{1}\right)$, again by $T$ as a $p$-contractive, we can find $u_{3} \in T\left(u_{2}\right)$ such that

$$
p\left(u_{2}, u_{3}\right) \leq r p\left(u_{1}, u_{2}\right) \text {. }
$$

Continuing this process, we obtain a sequence $\left\{u_{n}\right\}$ in $X$ such that $u_{n+1} \in T\left(u_{n}\right)$ and

$$
p\left(u_{n}, u_{n+1}\right) \leq r p\left(u_{n-1}, u_{n}\right) \text {, for all } n \in \mathbb{N} \text {. }
$$

Notice that we have

$$
p\left(u_{n}, u_{n+1}\right) \leq r p\left(u_{n-1}, u_{n}\right) \leq r^{2} p\left(u_{n-2}, u_{n-1}\right) \leq \cdots \leq r^{n} p\left(u_{0}, u_{1}\right),
$$

for each $n \in \mathbb{N}$. This gives,

$$
\begin{aligned}
p\left(u_{n}, u_{m}\right) & \leq p\left(u_{n}, u_{n+1}\right)+p\left(u_{n+1}, u_{n+2}\right)+\cdots+p\left(u_{m-1}, u_{m}\right) \\
& \leq r^{n} p\left(u_{0}, u_{1}\right)+r^{n+1} p\left(u_{0}, u_{1}\right)+\cdots+r^{m-1} p\left(u_{0}, u_{1}\right) \\
& \leq \frac{r^{n}}{1-r} p\left(u_{0}, u_{1}\right),
\end{aligned}
$$

where $n, m \in \mathbb{N}$ with $m \geq n$. Consequently,

$$
0 \leq \lim _{n \rightarrow \infty} \sup \left\{p\left(u_{n}, u_{m}\right): m \geq n\right\} \leq \lim _{n \rightarrow \infty} \frac{r^{n}}{1-r} p\left(u_{0}, u_{1}\right)=0 .
$$

This proves the first part of this lemma. Furthermore, the second part is followed from (2.6) and Lemma 1.7.

Lemma 2.3. Let $(X, d)$ be a complete metric space and $T: X \rightarrow 2^{X}$ be a p-contractive mapping. Then, there exist a sequence $\left\{w_{n}\right\}$ and $v_{0}$ in $\times$ such that $\left\{w_{n}\right\} \subset T\left(v_{0}\right)$ and $\left\{w_{n}\right\}$ converges to $v_{0}$.

Proof. Let $\theta: X \times X \times[0, \infty) \times[0, \infty) \rightarrow[0, \infty)$ be a mapping satisfying $(u 2) \sim(u 5)$ for this $u$-distance $p$.

Let $u_{0} \in X$ be chosen. By Lemma 2.2, we know that there exists $\left\{u_{n}\right\} \in \mathcal{O}\left(T, u_{0}\right)$ such that $\left\{u_{n}\right\}$ is a $p$-Cauchy sequence. Moreover, it satisfies

$$
p\left(u_{n}, u_{m}\right) \leq \frac{r^{n}}{1-r} p\left(u_{0}, u_{1}\right)
$$

where $n, m \in \mathbb{N}$ with $m \geq n$. Since $\left\{u_{n}\right\}$ is a $p$-Cauchy sequence in a metric complete space $(X, d)$, it is a convergent sequence, say $\lim _{n \rightarrow \infty} u_{n}=v_{0}$, for some $v_{0} \in X$. Consequently, by $\left(u_{3}\right)$ and (2.7), we have

$$
p\left(u_{n}, v_{0}\right) \leq \liminf _{m \rightarrow \infty} p\left(u_{n}, u_{m}\right) \leq \frac{r^{n}}{1-r} p\left(u_{0}, u_{1}\right) .
$$

For this $v_{0} \in X$, by using the $p$-contractiveness of mapping $T$, we can find a sequence $\left\{w_{n}\right\}$ in $T\left(v_{0}\right)$ such that 


$$
p\left(u_{n}, w_{n}\right) \leq r p\left(u_{n-1}, v_{0}\right)
$$

It follows that

$$
p\left(u_{n}, w_{n}\right) \leq r p\left(u_{n-1}, v_{0}\right) \leq \frac{r^{n}}{1-r} p\left(u_{0}, u_{1}\right),
$$

for any $n \in \mathbb{N}$.

Now we show that $\left\{w_{n}\right\}$ converges to $v_{0}$. In fact, since $\theta$ is a nondecreasing function in its third and fourth variables, then (2.8) and (2.9) imply

$$
\lim _{n \rightarrow \infty} \theta\left(u_{n}, u_{n}, p\left(u_{n}, v_{0}\right), p\left(u_{n}, v_{0}\right)\right)=0,
$$

and

$$
\lim _{n \rightarrow \infty} \theta\left(u_{n}, u_{n}, p\left(u_{n}, w_{n}\right), p\left(u_{n}, w_{n}\right)\right)=0 .
$$

Hence, by $(u 5)$, we conclude that $\lim _{n \rightarrow \infty} d\left(v_{0}, w_{n}\right)=0$. This means that $\left\{w_{n}\right\}$ converges to $v_{0}$, and the proof is completed.

For a metric space $(X, d)$, we will denote by $C l(X)$ the set of all closed subsets of $X$. In view of proving Lemma 2.3, we can obtain a fixed point theorem in the general metric space setting.

Theorem 2.4. Let $(X, d)$ be a metric space and $T: X \rightarrow 2^{X}$ be a p-contractive mapping. If there exist $u_{0}, v_{0} \in X$ and $\left\{u_{n}\right\} \in \mathcal{O}\left(T, u_{0}\right)$ such that

(i) $\lim _{n \rightarrow \infty} p\left(u_{n}, v_{0}\right)=0$;

(ii) $T\left(v_{0}\right) \in \operatorname{Cl}(X)$.

Then, $F(T) \neq \varnothing$. Furthermore, $v_{0} \in F(T)$.

Next, we provide some fixed point theorems for $p$-contractive mapping in a complete metric space.

Theorem 2.5. Let $(X, d)$ be a complete metric space and $T: X \rightarrow C l(X)$ be a p-contractive mapping. Then, there exists $v_{0} \in X$ such that $v_{0} \in T\left(v_{0}\right)$ and $p\left(v_{0}, v_{0}\right)=0$.

Proof. Let $u_{0} \in X$ be chosen. From Lemma 2.2 and Theorem 2.4, we know that there exist a $p$-Cauchy sequence $\left\{u_{n}\right\} \in \mathcal{O}\left(T, u_{0}\right)$ and $v_{0} \in F(T)$ such that $\left\{u_{n}\right\}$ converges to $v_{0}$

$$
\lim _{n \rightarrow \infty} \sup \left\{p\left(u_{n}, u_{m}\right): m \geq n\right\}=0,
$$

and

$$
p\left(u_{n}, v_{0}\right) \leq \frac{r^{n}}{1-r} p\left(u_{0}, u_{1}\right) .
$$

We now show that $p\left(v_{0}, v_{0}\right)=0$. Observe that, since $T$ is a $p$-contractive mapping and $v_{0} \in T\left(v_{0}\right)$, we can find $v_{1} \in T\left(v_{0}\right)$ such that

$$
p\left(v_{0}, v_{1}\right) \leq r p\left(v_{0}, v_{0}\right) \text {. }
$$

In fact, by using this process, we can obtain a sequence $\left\{v_{n}\right\}$ in $X$ such that $v_{n+1} \in T$ $\left(v_{n}\right)$ and 


$$
p\left(v_{0}, v_{n+1}\right) \leq r p\left(v_{0}, v_{n}\right), \text { for all } n \in \mathbb{N} .
$$

It follows that

$$
p\left(v_{0}, v_{n}\right) \leq r p\left(v_{0}, v_{n-1}\right) \leq \cdots \leq r^{n} p\left(v_{0}, v_{0}\right) .
$$

By using (2.11) and (2.12), we have

$$
\begin{aligned}
\lim _{n \rightarrow \infty} p\left(u_{n}, v_{n}\right) & \leq \lim _{n \rightarrow \infty}\left[p\left(u_{n}, v_{0}\right)+p\left(v_{0}, v_{n}\right)\right] \\
& =0 .
\end{aligned}
$$

Consequently, by using this one together with (2.10), we get

$$
\limsup _{n \rightarrow \infty} \sup \left\{p\left(u_{n}, v_{m}\right): m \geq n\right\} \leq \lim _{n \rightarrow \infty}\left[\sup \left\{p\left(u_{n}, u_{m}\right): m \geq n\right\}+\sup \left\{p\left(u_{m}, v_{m}\right): m \geq n\right\}\right]=0 .
$$

Thus, since $\left\{u_{n}\right\}$ is a $p$-Cauchy sequence, we know from (2.13) and Lemma 2.1 that $\left\{v_{n}\right\}$ is a $p$-Cauchy sequence and $\lim _{n \rightarrow \infty} d\left(u_{n}, v_{n}\right)=0$. Thus, since $(X, d)$ is a complete metric space, there exists $x_{0} \in X$ such that $\lim _{n \rightarrow \infty} v_{n}=x_{0}$. Consequently, by using (u3), we obtain

$$
p\left(v_{0}, x_{0}\right) \leq \liminf _{n \rightarrow \infty} p\left(v_{0}, v_{n}\right) \leq 0
$$

This implies

$$
p\left(v_{0}, x_{0}\right)=0 \text {. }
$$

On the other hand, since $\lim _{n \rightarrow \infty} u_{n}=v_{0}, \lim _{n \rightarrow \infty} v_{n}=x_{0}$ and $\lim _{n \rightarrow \infty} d\left(u_{n}, v_{n}\right)=0$, we know that $x_{0}=v_{0}$. Hence, from (2.14), we conclude that $p\left(v_{0}, v_{0}\right)=0$. This completes the proof.

Remark 2.6. Theorem 2.5 extends a result presented by Suzuki and Takahashi [9], from the concept of $w$-distance to the concept of $u$-distance.

By using Theorem 2.5, we can obtain the following result.

Corollary 2.7. Let $(X, d)$ be a complete metric space, and let $T: X \rightarrow X$ be a $p$-contractive mapping. Then, $T$ has a unique fixed point $v_{0} \in X$. Further, such $v_{0}$ satisfies $p$ $\left(v_{0}, v_{0}\right)=0$.

Proof. It follows from Theorem 2.5 that there exists $v_{0} \in X$ such that $T\left(v_{0}\right)=v_{0}$ and $p\left(v_{0}, v_{0}\right)=0$. Now if $y_{0}=T\left(y_{0}\right)$, we see that

$$
p\left(v_{0}, y_{0}\right)=p\left(T\left(v_{0}\right), T\left(y_{0}\right)\right) \leq r p\left(v_{0}, y_{0}\right),
$$

where $r \in[0,1)$ satisfies the condition of $p$-contractive mapping $T$. Consequently, since $r \in[0,1)$, we have $p\left(v_{0}, y_{0}\right)=0$. Hence, by $p\left(v_{0}, v_{0}\right)=0$ and Lemma 1.9, we conclude that $v_{0}=y_{0}$. This completes the proof.

Obviously, our Corollary 2.7 is a generalization of Banach contraction principle. Now we provide an interesting example.

Example 2.8. Let $a \in(1, \infty)$ be a fixed real number. Let $c$ and $d$ be two positive real numbers such that $c \in\left(1, \frac{2 a+1}{a}\right)$ and $d \in\left(a c-a, a c-\frac{a}{2}\right)$, respectively. Let $X=[0, a]$ and $d: X \times X \rightarrow[0, \infty)$ be a usual metric. Let us consider a mapping $T: X \rightarrow X$, which is defined by 


$$
T x=\left\{\begin{array}{lr}
\frac{x}{2} & \text { if } x \in\left[0, \frac{d}{c}\right) \\
c x-d & \text { if } x \in\left[\frac{d}{c}, a\right] .
\end{array}\right.
$$

Observe that for each $x, y \in\left[\frac{d}{c}, a\right]$, we have

$$
d(T x, T y)=c|x-y|>|x-y|=d(x, y),
$$

since $c>1$. This fact implies that the Banach contraction principle cannot be used for guaranteeing the existence of fixed point of our considered mapping $T$.

On the other hand, define now a function $p: X \times X \rightarrow[0, \infty)$ by

$$
p(x, y)=|x|, \quad \text { for all } x, y \in X .
$$

It follows that $p$ is a $u$-distance, see [11].

Let us choose $r=\frac{a c-d}{a}$. Notice that, by the choice of $d$, we have $r \in\left(\frac{1}{2}, 1\right)$. We will show that $T$ satisfies all hypotheses of our Corollary 2.7, with respect to this real number $r$ and $u$-distance $p$. To do this, we consider the following cases:

Case 1: If $x \in\left[0, \frac{d}{c}\right)$. We have

$$
p(T x, T y)=|T x|=\frac{x}{2}<r x=r p(x, y) .
$$

Case 2: If $x \in\left[\frac{d}{c}, a\right]$. We have

$$
p(T x, T y)=|c x-d| \leq\left(\frac{a c-d}{a}\right) x=r p(x, y) .
$$

By using above facts, we can show that all assumptions of Corollary 2.7 are satisfied. In fact, we can check that $F(T)=\{0\}$.

Remark 2.9. Example 2.8 shows that Corollary 2.7 is a genuine generalization of the Banach contraction principle.

\section{Acknowledgements}

The authors would like to thank the anonymous referees for a careful reading of the manuscript and helpful suggestions. Narin Petrot was supported by the Centre of Excellence in Mathematics, the commission on Higher Education, Thailand.

\section{Author details}

${ }^{1}$ Department of Mathematics, Faculty of Science, Naresuan University, Phitsanulok 65000, Thailand ${ }^{2}$ The Centre of Excellence in Mathematics, CHE, Si Ayuthaya Road, Bangkok 10400, Thailand

\section{Authors' contributions}

Both authors contributed equally in this paper. They read and approved the final manuscript.

\section{Competing interests}

The authors declare that they have no competing interests.

Received: 27 March 2011 Accepted: 8 November 2011 Published: 8 November 2011

\section{References}

1. Banach, S: Surles opérations dans les ensembles abstraits et leurs applications aux êquations intégrales. Fund Math. 3, 133-181 (1922)

2. Nadler, SB Jr: Multi-valued contraction mappings. Pac J Math. 30(2), 475-488 (1969) 
3. Cho, YJ, Hirunworakit, S, Petrot, N: Set-valued fixed points theorems for generalized contractive mappings without the Hausdorff metric. Appl Math Lett. 24, 1959-1967 (2011). doi:10.1016/j.aml.2011.05.030

4. Kada, O, Suzuki, T, Takahashi, W: Nonconvex minimization theorems and fixed point theorems in complete metric spaces. Math Japonica. 44(2), 381-391 (1996)

5. Sintunavart, W, Kumam, P: Coincidence and common fixed points for hybrid strict contractions without the weakly commuting condition. Appl Math Lett. 22, 1877-1881 (2009). doi:10.1016/j.aml.2009.07.015

6. Sintunavart, W, Kumam, P: Weak condition for generalized multi-valued $(f ; a ; \beta)$-weak contraction mappings. Appl Math Lett. 24, 460-465 (2011). doi:10.1016/j.aml.2010.10.042

7. Suzuki, T: Generalized distance and existence theorems in complete metric spaces. J Math Anal Appl. 253(2), 440-458 (2001). doi:10.1006/jmaa.2000.7151

8. Suzuki, T: Subrahmanyam's fixed point theorem. Nonlinear Anal. 71, 1678-1683 (2009). doi:10.1016/..na.2009.01.004

9. Suzuki, T, Takahashi, W: Fixed point theorems and characterizations of metric completeness. Topol Methods Nonlinear Anal. 8, 371-382 (1996)

10. Suwannawit, J, Petrot, N: Common fixed point theorem for hybrid generalized multivalued. Thai J Math. 9(2), 417-427 (2011)

11. Ume, J-S: Existence theorems for generalized distance on complete metric spaces. Fixed Point Theory Appl. 2010(397150), 21 (2010)

doi:10.1186/1687-1812-2011-78

Cite this article as: Hirunworakit and Petrot: Some fixed point theorems for contractive multi-valued mappings induced by generalized distance in metric spaces. Fixed Point Theory and Applications 2011 2011:78.

\section{Submit your manuscript to a SpringerOpen ${ }^{\odot}$} journal and benefit from:

- Convenient online submission

Rigorous peer review

- Immediate publication on acceptance

- Open access: articles freely available online

- High visibility within the field

- Retaining the copyright to your article

Submit your next manuscript at $\gg$ springeropen.com 